Article

\title{
Glycyrrhetic Acid Ameliorates Dextran Sulfate Sodium-Induced Ulcerative Colitis in Vivo
}

\author{
Yong-Deok Jeon ${ }^{1}$, Sa-Haeng Kang ${ }^{1}$, Keuk-Soo Bang ${ }^{1}$, Young-Nam Chang ${ }^{1}$, Jong-Hyun Lee ${ }^{2}$ \\ and Jong-Sik Jin ${ }^{1, *}$ \\ 1 Department of Oriental Medicine Resources, Chonbuk National University, 79 Gobongro, \\ Iksan 570-752(1), Korea; dugicom@nate.com (Y.-D.J.); rkdtkgod@naver.com (S.-H.K.); \\ ksbang@jbnu.ac.kr (K.-S.B.); chyn@jbnu.ac.kr (Y.-N.C.) \\ 2 Department of Pharmacy, College of Pharmacy, Dongduk Woman's University, 23-1 Wolgok-Dong, \\ SungBuk-Gu, Seoul 136-714, Korea; naturalmed@dongduk.ac.kr \\ * Correspondence: jongsik.jin@jbnu.ac.kr; Tel.: +82-63-850-0744 \\ Academic Editor: Derek J. McPhee \\ Received: 25 January 2016; Accepted: 14 April 2016; Published: 22 April 2016
}

\begin{abstract}
Glycyrrhizae Radix (GR) is a Korean traditional herb medicine that is widely used in clinical health care. Glycyrrhetic acid (GA) is an aglycone saponin extracted from GR that has anti-inflammatory, anti-cancer, and anti-viral effects. However, the anti-inflammatory effects of GA in colitis have not been reported. This study investigated the role of GA on ulcerative colitis in a dextran sulfate sodium (DSS)-induced mouse colitis model. DSS-treated mice displayed weight loss and shortened colon length compared with control mice. Mice administered GA showed less weight loss and longer colon length than the DSS-treated group. Interleukin (IL)-6, IL-1 $\beta$, and tumor necrosis factor-alpha were decreased by GA treatment. GA treatment also reduced DSS-induced microscopic damage to colon tissue. GA regulates the phosphorylation of transcription factors including nuclear factor-kappa B (NF- $\mathrm{kB}$ ) and IкB alpha, and regulates the expression of cycloxygenase-2 and prostaglandin $\mathrm{E}_{2}$. GA thus showed beneficial effects in a mouse model of colitis, implicating GA might be a useful herb-derived medicine in the treatment of ulcerative colitis.
\end{abstract}

Keywords: glycyrrhetic acid; ulcerative colitis; dextran sulfate sodium; anti-inflammation

\section{Introduction}

Ulcerative colitis (UC) is a chronic and relapsing inflammatory disease characterized by dysregulation of the immune function response and imbalanced release of cytokines and unresolved inflammatory progress associated with intestinal mucosa [1,2]. The inflammation reaction may be initiated by pro-inflammatory cytokines [3]. Patients with bowel disease have increased interleukin (IL)-6 in the intestinal mucosa and tumor necrosis factor-alpha (TNF- $\alpha$ ) in the blood and colon tissue. Immune cells, such as $T$ cells, intestinal epithelial cells, and macrophages, secrete various cytokines including TNF- $\alpha$, IL-1 family, IL-6, IL-8, and interferon-gamma (IFN- $\gamma$ ), which regulate the inflammatory response in UC. Elevated levels of cytokines have also been implicated in the pathogenesis of bowel disease [4,5].

Dextran sulfate sodium (DSS)-induced colitis is considered as a suitable model that represents the disease both morphologically and biochemically. Intake of DSS induces bloody stools, ulcerations, epithelial injury, and infiltration of inflammatory cells [6]. Histologically, DSS causes crypt abscesses and epithelioglandular hyperplasia in mice. These colon conditions are similar to acute and chronic UC in humans. DSS is toxic to gut epithelial cells of the basal crypts and affects the integrity of the mucosal barrier [7]. Thus, the DSS-induced colitis model is especially suitable to study the mechanism of inflammatory colitis. 
Cyclooxygenase-1 (COX-1) is a constitutive enzyme that catalyzes the production of prostaglandins (PGs), which protect the stomach from damage. COX-2 is induced by inflammatory stimuli, such as cytokines, and also catalyzes PG production that contributes to inflammation-related swelling [8]. COX-2 and PGE2 levels are raised in the inflamed mucosa of patients with UC [9].

Glycyrrhiza uralensis (GU) is a medicinal plant used in Europe and Asia for treating debilitating UC. It has been also used for diseases of the respiratory system and gastrointestinal tract [10]. Glycyrrhizae Radix (GR) has been traditionally used for treatment of cough, allergy, and bowel disease [11]. GR possesses various bioactive constituents that include saponins, flavonoids, and coumarins [12]. However, it is unknown whether the constituents of GR can regulate intestinal inflammation. Glycyrrhetic acid (GA) is a triterpenoid saponin found in GU as a hydrolyzed metabolite of glycyrrhizin [13]. Recent studies have demonstrated that GA has strong antioxidant, anti-inflammation, and anti-cancer effects [14]. GA can reduce the oxidative stress caused by carbon tetrachloride, reduces production of pro-inflammatory cytokines, and repress immune function [15]. These results suggest that GA has inhibitory effects on DSS-induced colitis model.

To explore the potential of GA as a useful therapeutic in UC, we examined its effects on DSS-induced UC in a mouse model. The aims were to evaluate the effect of GA on clinical signs including weight loss, colon shortening, diarrhea, and gross bleeding, and to investigate the role of GA on inflammatory mediators in DSS-treated mice.

\section{Results}

\subsection{Effects of GA on Clinical Signs in DSS-Induced Colitis}

When mice were treated with DSS to induce colitis, body weight was reduced and colon length was shortened at day 10 by $19.02 \pm 1.51 \mathrm{~g}$ and $28.6 \%$ respectively, compared to the control group (Figures 1A and 2A,B). Both GA 10 and GA $50 \mathrm{mg} / \mathrm{kg}$ alleviated the effects of DSS on body weight loss by $20.86 \pm 1.76 \mathrm{~g}$ and $22.05 \pm 1.25 \mathrm{~g}$, and colon shortening by $13.2 \%$ and $12.7 \%$, respectively (Figure 1B). Disease activity index (DAI) scores were increased at day 10 by $4.0 \pm 1.00$ in DSS-treated group, compared to the control group. GA also attenuated the DSS-mediated increase in DAI scores at day 10 by $2.8 \pm 0.45,2.2 \pm 0.84 ;$ GA 10, GA $50 \mathrm{mg} / \mathrm{kg}$.

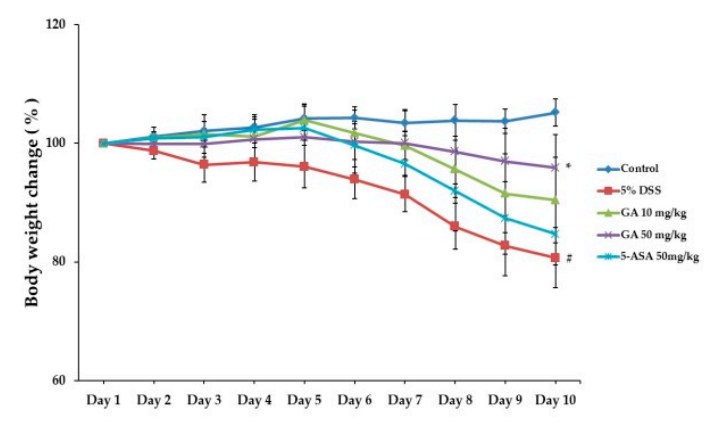

(A)

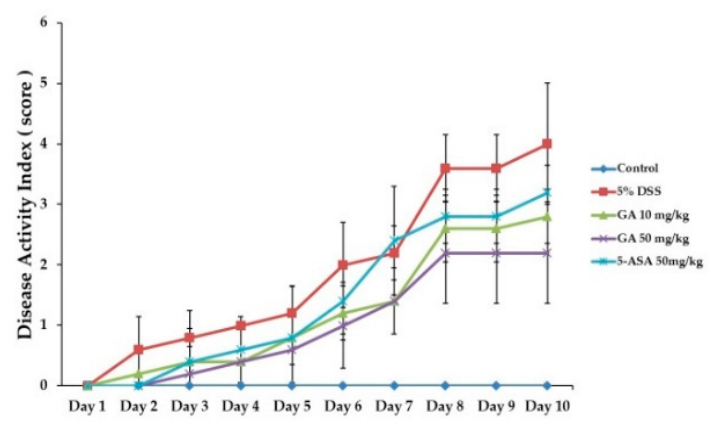

(B)

Figure 1. Effects of GA on clinical signs in DSS-induced colitis. (A) Body weight was measured at the same time on the experimental days; (B) Disease activity index score in the five study groups. Values represent mean \pm S.E.M. $(n=6)$. Data were analyzed by Student's $t$-test ${ }^{\#} p<0.05$ vs. control and $*<<0.05$ vs. DSS alone). 


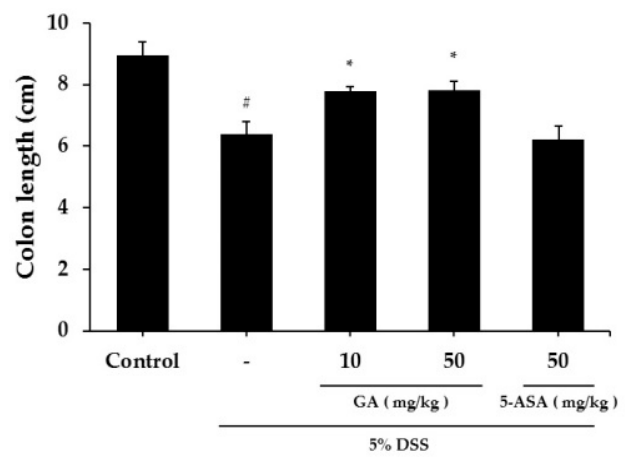

(A)

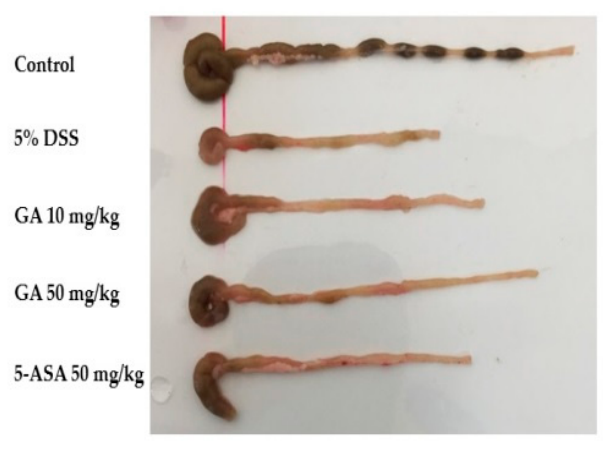

(B)

Figure 2. Effects of GA on DSS-induced colon shortening. (A) Average colon length in $\mathrm{cm}$ measured after 10 days at the time of sacrifice; (B) Representative colons of each group. Values represent mean \pm S.E.M. $(n=6)$. Data were analyzed by Student's $t$-test $\left({ }^{\#} p<0.05\right.$ vs. control and ${ }^{*} p<0.05$ vs. DSS alone).

\subsection{Effects of GA on Inflammatory Cytokines Level in DSS-Induced UC}

Serum IL-6 level was significantly higher in the DSS treatment group $(2.394 \pm 0.246 \mathrm{ng} / \mathrm{mL})$ than in the control group $(0.839 \pm 0.227 \mathrm{ng} / \mathrm{mL}$ ) (Figure 3A). IL-6 level was lower in the GA $50 \mathrm{mg} / \mathrm{kg}$ group $(1.943 \pm 0.152 \mathrm{ng} / \mathrm{mL})$ than the DSS-treated group. The serum TNF- $\alpha$ level was also increased in the DSS treatment group $(24.376 \pm 1.76 \mathrm{pg} / \mathrm{mL})$ compared to the control group $(8.943 \pm 1.847 \mathrm{pg} / \mathrm{mL})$, but was significantly inhibited in the GA $50 \mathrm{mg} / \mathrm{kg}$ group $(18.441 \pm 2.246 \mathrm{pg} / \mathrm{mL}$ ) (Figure 3B). The serum IL-1 $\beta$ level was increased in the DSS treatment group $(38.105 \pm 3.152 \mathrm{pg} / \mathrm{mL})$ compared to the control group $(14.318 \pm 3.206 \mathrm{pg} / \mathrm{mL}$ ) (Figure $3 \mathrm{C}$ ). IL-1 $\beta$ levels were lower in GA treatment groups (GA $10 \mathrm{mg} / \mathrm{kg} ; 31.416 \pm 1.406 \mathrm{pg} / \mathrm{mL}, \mathrm{GA} 50 \mathrm{mg} / \mathrm{kg} ; 21.721 \pm 2.548 \mathrm{pg} / \mathrm{mL}$ ).

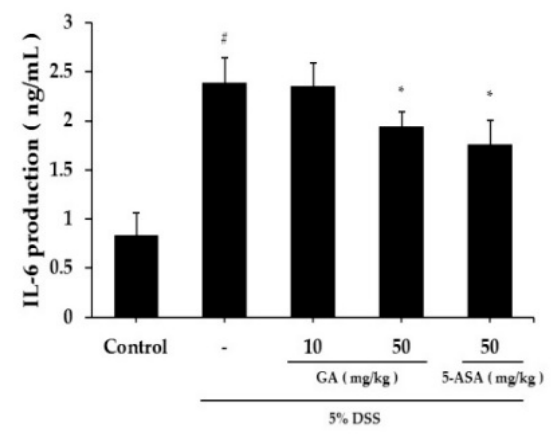

(A)

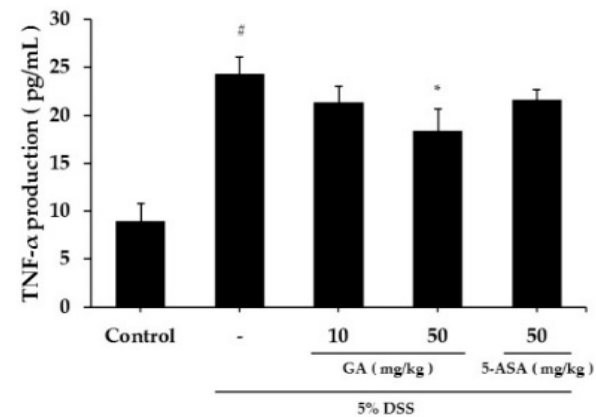

(B)

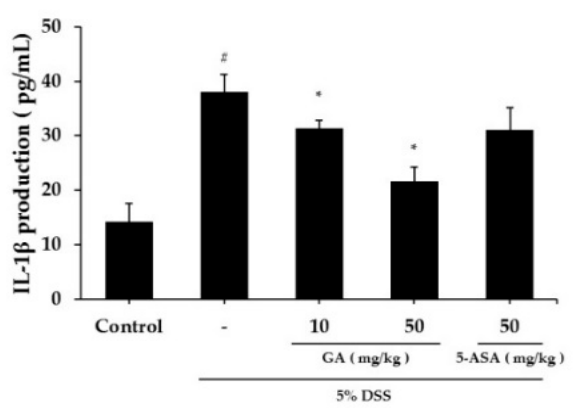

(C)

Figure 3. Effects of inflammatory cytokines levels in DSS-induced UC. (A) IL-6 production in mouse serum at day 10; (B) TNF- $\alpha$ production in mouse serum at day 10; (C) IL-1 $\beta$ production in mouse serum at day 10. Values represent mean \pm S.E.M. $(n=6)$. Data were analyzed by Student's $t$-test ( ${ }^{\#} p<0.05$ vs. control and ${ }^{*} p<0.05$ vs. DSS alone). 


\subsection{Effects of GA on Transcription Factors in DSS-Induced UC}

Nuclear factor-kappa B (NF- $\mathrm{kB}$ ) is an important transcription factor of inflammation reactions [16]. The effect of GA on the activation of NF-KB was investigated (Figure 4). Phosphorylation of IKB $\alpha$ and NF- $\mathrm{KB}$ in the colon tissue was inhibited by GA treatment. These results suggested that GA can inhibit the activation of transcription factors in UC.

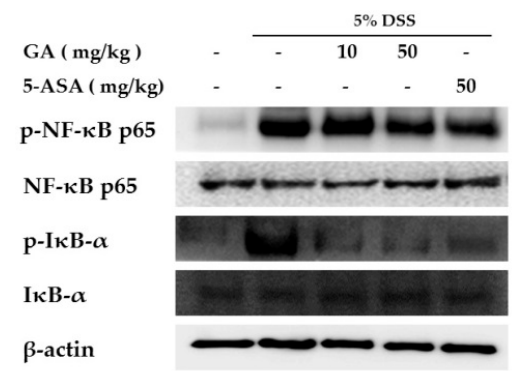

(A)

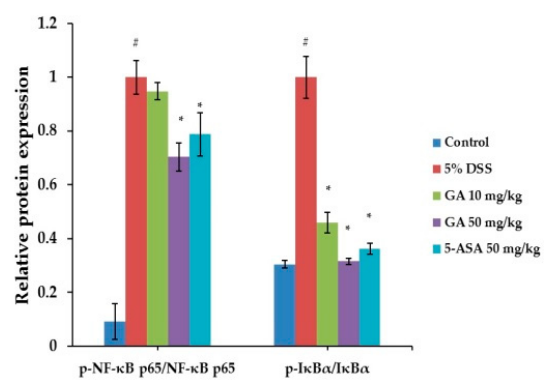

(B)

Figure 4. Effects of GA on transcription factors in DSS-induced UC. (A) Phosphorylation of IKB $\alpha$ and phosphorylation of NF- $\kappa$ B were assayed by Western blot; (B) Relative ratio of phospho-I $\mathrm{B} \alpha \alpha$ and NF- $\mathrm{B}$ p65 calculated using an image analyzer. Values represent mean \pm S.E.M. $(n=6)$. Data were analyzed by Student's $t$-test ( ${ }^{\#} p<0.05$ vs. control and ${ }^{*} p<0.05$ vs. DSS alone).

\subsection{Effects of GA on Epithelial Injury in DSS-Induced UC}

Mucosal thickness is regarded as an indicator of normal mucosal condition. DSS causes epithelial injury and infiltration of inflammatory cells, including mast cells [17]. We compared the colon tissue condition between the DSS-treated and control groups (Figure 5A). GA treatment attenuated the effects induced by DSS treatment (Figure 5B). GA treatment also reduced the DSS-mediated microscopic damage to the colonic tissue.

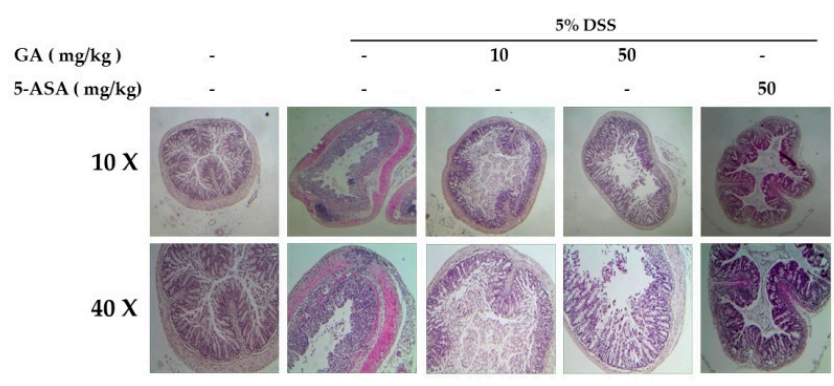

(A)

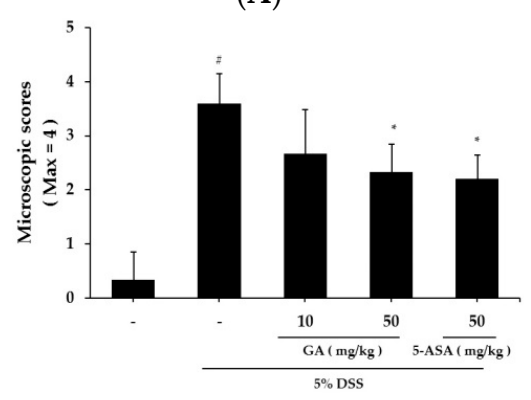

(B)

Figure 5. Effects of GA on epithelial injury in DSS-induced UC. (A) Paraffin sections of colonic tissue were stained with hematoxylin \& eosin, and then observed by microscope $(10 \times$ and $40 \times)$; (B) Microscopic scores. Values represent mean \pm S.E.M. $(n=6)$. Data were analyzed by Student's $t$-test ( ${ }^{\#} p<0.05$ vs. control and * $p<0.05$ vs. DSS alone). 


\subsection{Effects of GA on COX-2 and PGE 2 Expression in DSS-Induced UC}

The effects of GA on COX-2 expression in colon tissues were demonstrated using western blot analysis (Figure 6A). DSS markedly induced COX-2 expression in colon tissue vs. control group, but increased COX-2 expression was significantly reduced by GA administration. Relative expression levels of COX-2 are presented in Figure 6B. COX-2 catalyzed $\mathrm{PGE}_{2}$ biosynthesis, and we examined whether GA affects $\mathrm{PGE}_{2}$ levels (Figure 6C). PGE $_{2}$ levels were enhanced by DSS, and this increase was significantly inhibited by GA administration.

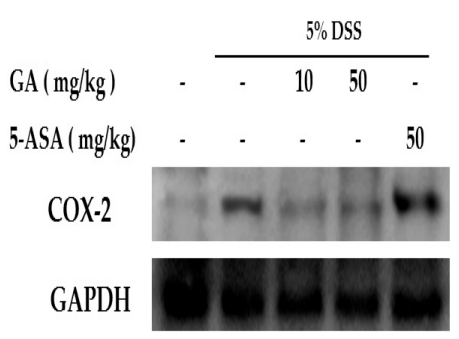

(A)

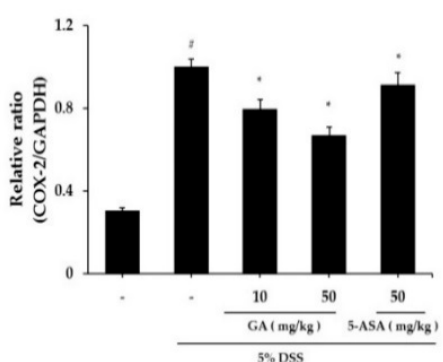

(B)

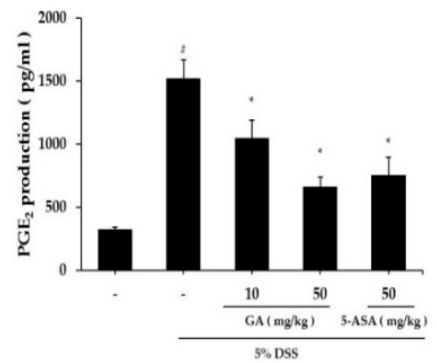

(C)

Figure 6. Effects of GA on COX-2 and $\mathrm{PGE}_{2}$ expression in DSS-induced UC. COX-2 levels were determined by western blot analysis, and $\mathrm{PGE}_{2}$ levels using $\mathrm{PGE}_{2}$ assay kits. (A) Western blot analysis was used to determine COX-2 levels in colonic tissues. Data shown are representative of three independent experiments; (B) COX-2/GAPDH ratios were determined by densitometry; (C) $\mathrm{PGE}_{2}$ production in colonic tissues. Values represent mean \pm S.E.M. $(n=6)$. Data were analyzed by Student's $t$-test (\# $p<0.05$ vs. control and * $p<0.05$ vs. DSS alone).

\section{Discussion}

Inflammatory bowel diseases (IBDs), including Crohn's disease and UC, are chronic relapsing intestinal inflammatory disorders. Even if the pathogenic mechanism of IBDs is barely understood, recent evidence suggests that deviant immune responses cause the IBD symptoms [18-21]. UC symptoms can include weight loss and bloody diarrhea [22]. Immune modulators, such as sulfasalazine and glucocorticosteroids, are the most used therapies for UC [23]. These therapies can cause adverse side effects like vomiting, anemia, and generalized edema. Thus, interest in the use of traditional herbal medicines for inflammatory chronic disease has grown [24].

There are over the 20 animal models of colitis. DSS-induced colitis is one of the most suitable experimental models [25]. Using this model, we demonstrate herein that GA alleviates clinical signs of UC (weight loss, colon shortening, diarrhea and occult/gross bleeding).

IL-6, TNF- $\alpha$, and IFN- $\gamma$ are pathogenic mediators of murine colitis [26,27]. In IBD, immune cells including T lymphocytes and macrophages secrete inflammatory cytokines in the area of inflammation. These activated cells modulate the balance between pro- and anti-inflammatory cytokines. IL- 6 and TNF- $\alpha$ expression is elevated in the rectal mucosa of UC patients [28]. Presently, GA suppressed the DSS-induced increase in IL- 6 , TNF- $\alpha$, and IL- $1 \beta$ in mouse serum and tissues.

In the inflammation reaction, COX-1 protein activity rarely changes, but COX-2 production dramatically increases, leading to the increased production of PGs [29]. Among the PGs, $\mathrm{PGE}_{2}$ is increased in the intestines of IBD patients [30]. 5-Aminosalicylic acid is used to treat IBD by inhibiting COX-2 activation [31]. COX-2 and $\mathrm{PGE}_{2}$ play key role as mediators in UC. Presently, GA inhibited the DSS-induced activation of COX-2 and $\mathrm{PGE}_{2}$. The results suggest that the anti-inflammatory effect of GA is attributable to the regulation of COX-2 in DSS-induces colitis. We also found that GA reduced epithelial injury and inflammatory cell infiltration into colon tissue.

Pro-inflammatory mediators, such as inflammatory cytokines and chemokines, are controlled by the activity of transcriptional factors. The activation of NF- $\mathrm{kB}$ is important in the pathogenesis of 
IBD [32-34]. DSS-induced I $\kappa \mathrm{B} \alpha$ phosphorylation and phosphorylation of NF- $\mathrm{kB}$ p65 in colonic tissues were suppressed by GA treatment.

GR is used as a traditional herbal medicine in many Asian countries. Glycyrrhizin is the principal component of GR, and has been used for treatment of liver disease, allergic reactions, and gastric ulcers [35]. GA is a GR component which has an anti-inflammatory effect on lipopolysaccharide-induced liver injury and inhibition of hepatic lipotoxicity [36]. GA is a biologically active metabolite resulting from glycyrrhizin's presystemic hydrolysis. Although GA has a protective effect on hepatic injury and an anti-inflammatory effect on LPS-stimulated macrophages [37], its regulatory effects on intestine inflammation have not been reported. GA is not cytotoxic to RAW264.7 macrophages in various concentrations [38]. GA also regulates nitric oxide generation, phosphorylation of mitogen activated protein kinaes (MAPKs), and NF- $\mathrm{KB}$ activation in infected bone marrow-derived macrophages [39]. These compounds might be useful for the prevention of inflammatory disease.

In summary, GA has anti-inflammatory effects in a DSS-induced colitis model. GA might inhibit inflammation by regulating the mediators like COX-2 and NF- $\mathrm{kB}$. GA could be used for therapeutic agent to treat colitis.

\section{Materials and Methods}

\subsection{Reagents}

GA was purchased from Tokyo Chemical Industry CO (Tokyo, Japan). DSS was purchased from MP Bio (Santa Ana, CA, USA). 5-Aminosalicylic acid, 10\% neutral-buffer, and eosin were purchased from Sigma-Aldrich (St. Louis, MO, USA). Purified, biotin, standard anti-mouse IL-6 and TNF- $\alpha$, and (2,2'-azinobis [3-ethylbenzothiazoline-6-sulfonic acid] diammonium salt) substrate were purchased from BD Bioscience (San Diego, CA, USA). Lysis buffer was purchased from iNtRON Biotech (Seongnam, Gyeonggi-do, Korea). COX-2, NF-kB p65, pNF-кB p65, IкB $\alpha$, and $\mathrm{pI} \kappa \mathrm{B} \alpha$ were purchased from Cell Signaling Technology (Boston, MA, USA). Glyceraldehyde phosphate dehydrogenase (GAPDH) was purchased from Santa Cruz Biotechnology (Santa Cruz, CA, USA). Hematoxylin was purchased from Muto Pure Chemicals (Hongo, Bunkyo-ku, Tokyo, Japan).

\subsection{Mice}

Male BALB/c, 6-week-old mice obtained from SAMTACO (Osan, Kyungki-Do, Korea) were acclimatized in a specific pathogen-free environment under controlled conditions $\left(22 \pm 2{ }^{\circ} \mathrm{C}\right.$ with a $12 \mathrm{~h}$ light/dark cycle) for one week. The mice were housed in five colony cages with six mice per cage.

\subsection{DSS-Induced UC}

All experimental protocols (CBU2016-0021) were approved by the Committee on the Care of Laboratory Animal Resources, Chonbuk National University and were conducted in accordance with the Guide for the Care and Use of Laboratory Animals. Acute colitis was induced by administering drinking water containing $5 \%(w / v)$ DSS to mice for 10 days. Thirty mice were weighted before the experiment, and were divided into five groups with six mice per group. Group 1 comprised untreated mice. Mice in group 2 received DSS. In group 3 and group 4, mice with induced colitis were treated with GA at 50 and $10 \mathrm{mg} / \mathrm{kg}$, respectively. In group 5, mice with induced colitis were treated with $50 \mathrm{mg} / \mathrm{kg} 5$-aminosalicylic acid as the reference drug. Mice were checked daily for body weight, stool consistency, and the presence of gross bleeding. GA was diluted with purified water and orally administered once a day during the 10 days of DSS treatment, after which the mice were sacrificed.

\subsection{Disease Activity Index (DAI)}

Intestinal disease activity was assessed based on the weight loss, presence of diarrhea accompanied by blood and mucus, and colonic shortening [40]. DAIs were calculated by scoring weight loss, diarrhea, and rectal bleeding based on the previously described scoring system [41] shown 
in Table 1. Weight loss was defined as the difference between initial and final weights, and diarrhea as the absence of fecal pellet formation and the presence of continuous fluid fecal material in the colon. Rectal bleeding was assessed based on the presence of diarrhea containing visible blood and on the presence of gross rectal bleeding. DAI values were calculated as \{(weight loss score) + (diarrhea score) + (rectal bleeding score) $\} / 4$. The DAI was determined by three investigators blinded to the protocol. The clinical parameters used in the present study were chosen to represent the subjective clinical symptoms observed in human UC.

Table 1. Criteria for disease activity index.

\begin{tabular}{cccc}
\hline Score & Weight Loss (\%) & Stool Consistency & Bloodstain or Gross Bleeding \\
\hline 0 & None & Normal & Negative \\
1 & $1-5$ & Loose stool & Negative \\
2 & $5-10$ & Loose stool & Positive \\
3 & $10-15$ & Diarrhea & Positive \\
4 & $>15$ & Diarrhea & Gross bleeding \\
\hline
\end{tabular}

\subsection{Enzyme-Linked Immunosorbent Assay (ELISA)}

Levels of IL-6 and TNF- $\alpha$ in the serum and tissue were measured using an enzyme-linked immunosorbent assay (ELISA), as previously described [42]. Briefly, 96-well plates (SPL Life Science, Seoul, Korea) were coated with $100 \mu \mathrm{L}$ of anti-mouse monoclonal antibody $(1.0 \mathrm{mg} / \mathrm{mL}$ at $\mathrm{pH} 7.4 \mathrm{in}$ phosphate buffered saline [PBS] ) and incubated overnight at $4{ }^{\circ} \mathrm{C}$. After additional washes, $50 \mu \mathrm{L}$ of sample, or IL-6 and TNF- $\alpha$ standard was added and incubated at room temperature for $2 \mathrm{~h}$. Plates were washed and $0.2 \mu \mathrm{g} / \mathrm{mL}$ of biotinylated anti-mouse antibody was added and incubated at room temperature for $2 \mathrm{~h}$. After washing, avidin-peroxidase was added and plates were incubated for $30 \mathrm{~min}$ at $37^{\circ} \mathrm{C}$. The plates were then washed again and $\left(2,2^{\prime}\right.$-azinobis [3-ethylbenzothiazoline-6-sulfonic acid]-diammonium salt) substrate was added. Color development was measured at $405 \mathrm{~nm}$ using an automated microplate ELISA reader (Molecular Devices, Sunnyvale, CA, USA). Standard curves were prepared using serial dilutions of recombinant antibody. Protein concentrations were measured using bicinchoninic acid (BCA) protein assay reagent (Bio-Rad, Hercules, CA, USA).

\subsection{Western Blot Analysis}

Distal colons were homogenized in lysis buffer (iNtRON Biotech, Korea) and centrifuged at 13,000 rpm for $5 \mathrm{~min}$. The supernatants were transferred to fresh tubes and protein concentrations were determined using BCA protein assay reagent. Lysates (50 $\mu \mathrm{g}$ protein) were separated by 10\% SDS-PAGE and transferred to membranes (Amersham Pharmacia Biotech, Piscataway, NJ, USA), which were blocked with 5\% skim milk in PBS-Tween-20 (PBST) for $1 \mathrm{~h}$ at room temperature. Membranes were incubated overnight with primary antibodies against COX-2, NF- $\kappa B$ p $65, \mathrm{pNF}-\kappa \mathrm{B}$ p65, IкB $\alpha$ and $\mathrm{pI} \kappa \mathrm{B} \alpha$ and GAPDH, and washed three times with PBST. Blots were incubated with secondary antibody for $1 \mathrm{~h}$ at room temperature. Antibody-specific proteins were visualized using an enhanced chemiluminescence detection system (Amersham, Newark, NJ, USA). Protein densities were quantified by densitometry.

\subsection{Histological Processing}

Mice were sacrificed at the end of the experiment. The entire colon was dissected and flushed with ice-cold PBS. Sections of rectums were taken and fixed in 10\% neutral-buffered formalin (Sigma-Aldrich) for $24 \mathrm{~h}$ at room temperature and embedded in paraffin to provide sections for histological evaluation. Severity of colitis was evaluated in sections stained with hematoxylin and eosin by two independent observers blinded to the experimental conditions according to modified criteria [43] summarized in Table 2. 
Table 2. Criteria for assessment of microscopic rectal damage.

\begin{tabular}{cc}
\hline Score & Remarks \\
\hline 0 & Normal colonic mucosa \\
1 & Loss of one-third of the crypts \\
2 & Loss of two-third of the crypts \\
3 & Lamina propria covered with single layer of epithelial cells with mild inflammatory cell infiltration \\
4 & Erosions and marked inflammatory cell infiltration \\
\hline
\end{tabular}

Mucosal damage was scored as $0-4$ based on the loss of crypt (mucosa) and infiltration of inflammatory cells (maximum score $=4$ ).

\section{8. $P G E_{2}$ Assay}

Distal colons were homogenized in lysis buffer, and centrifuged at 13,000 rpm for $5 \mathrm{~min}$. $\mathrm{PGE}_{2}$ levels were quantified using immunoassay kits according to the manufacturer's instructions (Enzo Life Science, East Farmingdale, NY, USA).

\subsection{Statistical Analysis}

The results are presented as mean \pm S.E.M of at least three independent experiments. Results were analyzed using PASW Statistics 18.0 program. Student's $t$-test was used to determine statistically significant differences. $p<0.05$ was considered significant.

\section{Conclusions}

GA reduces colon length shortening and loss body weight by DSS treatment. GA regulates the levels of inflammatory mediators such as IL-6, TNF- $\alpha$, and IL- $1 \beta$ in DSS-induced colitis in mice. GA treatment suppresses $\mathrm{PGE}_{2}$ production. It also reduces epithelial injury in DSS-induced UC. This study provides experimental evidence to show that GA might be a useful therapy in the treatment of UC.

Acknowledgments: This research was supported by Basic Science Research Program through the National Research Foundation of Korea (NRF) funded by the Ministry of Science, ICT \& Future Planning (2015R1C1A1A01054675) and the Industrial Technology Research Infrastructure Program (N0000004) funded by the Ministry of Trade, Industry and Energy (Sejong, Korea).

Author Contributions: Yong-Deok Jeon and S.-H. Kang performed the in vivo mouse model experiment and analyzed the data. Y.-N. Chang, J.-H. Lee and K.-S. Bang provided technical and material support. Y.-D. Jeon and J.-S. Jin collected the data, undertook the statistical analyses, and wrote the manuscript. J.-S. Jin designed and supervised the study, including editing of the manuscript. All authors contributed to and have approved the final manuscript.

Conflicts of Interest: The authors declare no conflict of interest.

\section{References}

1. Arita, M.; Yoshida, M.; Hong, S.; Tjonahen, E.; Glickman, J.N.; Petasis, N.A.; Blumberg, R.S.; Serhan, C.N.; Resolvin, E. Anendogenous lipid mediator derived from omega-3 eicopentanoic acid, protects against 2,4,6-trini-trobenzene sulfonic acid-induced colitis. PNAS 2005, 102, 7671-7676. [CrossRef] [PubMed]

2. Libby, P. Inflammation in atherosclerosis. Nature 2002, 420, 868-874. [CrossRef] [PubMed]

3. Li, Y.; de Haar, C.; Chen, M.; Deuring, J.; Gerrits, M.M.; Smits, R.; Xia, B.; Kuipers, E.J.; van der Woude, C.J. Disease-related expression of the IL6/STAT3/SOCS3 signaling pathway in ulcerative colitis and ulcerative colitis-related carcinogenesis. Gut 2010, 59, 227-235. [CrossRef] [PubMed]

4. Ogata, H.; Hibi, T. Cytokine and anti-cytokine therapies for inflammatory bowel disease. Curr. Pharm. Des. 2003, 9, 1107-1113. [CrossRef] [PubMed]

5. Papadakis, K.A.; Targan, S.R. Role of cytokines in the pathogenesis of inflammatory bowel disease. Annu. Rev. Med. 2000, 51, 289-298. [CrossRef] [PubMed]

6. Cooper, H.S.; Murthy, S.N.; Shah, R.S.; Sedergran, D.J. Clinicopathologic study of dextran sulfate sodium experimental murine colitis. Lab. Investig. 1993, 69, 238-249. [PubMed] 
7. Okayasu, I.; Hatakeyama, S.; Yamada, M.; Ohkusa, T.; Inagaki, Y.; Nakaya, R. A novel method in the induction of reliable experimental acute and chronic ulcerative colitis in mice. Gastroenterology 1990, 98, 694-702. [PubMed]

8. Roberts, P.J.; Morgan, K.; Miller, R.; Hunter, J.O.; Middleton, S.J. Neuronal COX-2 expression in human myenteric plexus in active inflammatory bowel disease. Gut 2001, 48, 468-472. [CrossRef] [PubMed]

9. MacDonald, T.T.; Murch, S.H. Aetiology and pathogenesis of chronic inflammatory bowel disease. Baillieres Clin. Gastroenterol. 1994, 8, 1-34. [CrossRef]

10. Asl, M.N.; Hosseinzadeh, H. Review of pharmacological effects of Glycyrrhiza sp. and its bioactive compounds. Phytother. Res. 2008, 22, 709-724. [CrossRef] [PubMed]

11. Chang, Y.I.; Chen, C.L.; Kuo, C.L.; Chen, B.C.; You, J.S. Glycyrrhetinic acid inhibits ICAM-1 expression via blocking JNK and NF-kB pathways in TNF- $\alpha$-activated endothelial cells. Acta Pharmacol. Sin. 2010, 31, 546-553. [CrossRef] [PubMed]

12. Wang, W.; Luo, M.; Fu, Y.; Wang, S.; Efferth, T.; Zu, Y. Glycyrrhizic acid nanoparticles inhibit LPS-induced inflammatory mediators in 264.7 mouse macrophages compared with unprocessed glycyrrhizic acid. Int. J. Nanomed. 2013, 8, 1377-1383.

13. Kim, Y.J.; Lee, C.S. Glycyrrhizin attenuates MPTP neurotoxicity in mouse and MPP-induced cell death in PC12 cells. Korean J. Physiol. Pharmacol. 2008, 12, 65-71. [CrossRef] [PubMed]

14. Matsui, S.; Matsumoto, H.; Sonoda, Y.; Ando, K.; Aizu-Yokota, E.; Sato, T.; Kasahara, T. Glycyrrhizin and related compounds down-regulate production of inflammatory chemokines IL-8 and eotaxin 1 in a human lung fibroblast cell line. Int. Immunopharmacol. 2004, 4, 1633-1644. [CrossRef] [PubMed]

15. Agarwal, M.K.; Iqbal, M.; Athar, M. Inhibitory effect of 18 $\beta$-glycyrrhetinic acid on 12-O-tetradecanoyl phorbol-13-acetate-induced cutaneous oxidative stress and tumor promotion in mice. Redox Rep. 2005, 10, 151-157. [CrossRef] [PubMed]

16. Barnes, P.J.; Karin, M. Nuclear factor- $\mathrm{kB}$ : A pivotal transcription factor in chronic inflammatory diseases. N. Engl. J. Med. 1997, 336, 1066-1071. [CrossRef]

17. Kim, D.S.; Ko, J.H.; Jeon, Y.D.; Han, Y.H.; Kim, H.J.; Poudel, A.; Jung, H.J.; Ku, S.K.; Park, S.H.; Park, J.H.; et al . Ixeris dentate NAKAI reduces clinical score and HIF-1 expression in experimental colitis in mice. Evid. Based Complement. Altern. Med. 2013. [CrossRef]

18. Dharmani, P.; Chadee, K. Biologic therapies against inflammatory bowel disease: A dysregulated immune system and the cross talk with gastrointestinal mucosa hold the key. Curr. Mol. Pharmacol. 2008, 1, $195-212$. [CrossRef] [PubMed]

19. Strober, W.; Fuss, I.; Mannon, P. The fundamental basis of inflammatory bowel disease. J. Clin. Investig. 2007, 117, 514-521. [CrossRef] [PubMed]

20. Sartor, R.B. Microbial influences in inflammatory bowel diseases. Gastroenterology 2008, 134, 577-594. [CrossRef] [PubMed]

21. Podolsky, D.K. Inflammatory bowel disease. N. Engl. J. Med. 2002, 347, 417-429. [CrossRef] [PubMed]

22. Rufo, P.A.; Bousvaros, A. Current therapy of inflammatory bowel disease in children. Paediatr. Drugs 2006, 8 , 279-302. [CrossRef] [PubMed]

23. Ishiguro, Y.; Ohkawara, T.; Sakuraba, H.; Yamagata, K.; Hiraga, H.; Yamaguchi, S.; Fukuda, S.; Munakata, A.; Nakane, A.; Nishihira, J. Macrophage migration inhibitory factor has a proinflammatory activity via the p38 pathway in glucocorticoid-resistant ulcerative colitis. Clin. Immunol. 2006, 120, 335-341. [CrossRef] [PubMed]

24. Sandborn, W.J.; Targan, S.R. Biologic therapy of inflammatory bowel disease. Gastroenterology 2002, 122, 1592-1608. [CrossRef] [PubMed]

25. Wirtz, S.; Neufert, C.; Weigmann, B.; Neurath, M.F. Chemically induced mouse models of intestinal inflammation. Nat. Protoc. 2007, 2, 541-546. [CrossRef] [PubMed]

26. Myers, K.J.; Murthy, S.; Flanigan, A.; Witchell, D.R.; Butler, M.; Murray, S.; Siwkowski, A.; Goodfellow, D.; Madsen, K.; Baker, B. Antisense oligonucleotide blockade of tumor necrosis factor- $\alpha$ in two murine models of colitis. J. Pharmacol. Exp. Ther. 2003, 304, 411-424. [CrossRef] [PubMed]

27. Naito, Y.; Takagi, T.; Uchiyama, K.; Kuroda, M.; Kokura, S.; Ichikawa, H.; Yanagisawa, R.; Inoue, K.; Takano, H.; Satoh, M.; et al. Reduced intestinal inflammation induced by dextran sodium sulfate in interleukin-6-deficient mice. Int. J. Mol. Med. 2004, 14, 191-196. [CrossRef] [PubMed] 
28. Atreya, R.; Zimmer, M.; Bartsch, B.; Waldner, M.J.; Atreya, I.; Neumann, H.; Hildner, K.; Hoffman, A.; Kiesslich, R.; Rink, A.D.; et al. Antibodies against tumor necrosis factor (TNF) induce T-cell apoptosis in patients with inflammatory bowel diseases via TNF receptor 2 and intestinal CD14 ${ }^{+}$macrophages. Gastroenterology 2011, 141, 2026-2038. [CrossRef] [PubMed]

29. Morita, I. Distinct functions of COX-1 and COX-2. Prostaglandins Other Lipid Mediat. 2002, 68-69, 165-175. [CrossRef]

30. Wiercińska-Drapało, A.; Flisiak, R.; Prokopowicz, D. Effects of ulcerative colitis activity on plasma and mucosal prostaglandin $\mathrm{E}_{2}$ concentration. Prostaglandins Other Lipid Mediat. 1999, 58, 159-165. [CrossRef]

31. Lauritsen, K.; Laursen, L.S.; Kjeldsen, J.; Bukhave, K.; Hansen, T.K.; Rask-Madsen, J. Effects of mesalazine on the formation of lipoxygenase and cyclooxygenase products. Adv. Exp. Med. Biol. 1995, 371, 1301-1306.

32. Perkins, N.D.; Gilmore, T.D. Good cop, bad cop: The different faces of NF-кB. Cell Death Differ. 2006, 13, 759-772. [CrossRef] [PubMed]

33. Hayden, M.S.; Ghosh, S. Signaling to NF-kB. Genes Dev. 2004, 18, 2195-2224. [CrossRef] [PubMed]

34. Lawrence, T.; Bebien, M.; Liu, G.Y.; Nizet, V.; Karin, M. IKK $\alpha$ limits macrophage NF- $\kappa B$ activation and contributes to the resolution of inflammation. Nature 2005, 434, 1138-1143. [CrossRef] [PubMed]

35. Fiore, C.; Eisenhut, M.; Ragazzi, E.; Zanchin, G.; Armanini, D. A history of the therapeutic use of liquorice in Europe. J. Ethnopharmacol. 2005, 99, 317-324. [CrossRef] [PubMed]

36. Yoshida, T.; Abe, K.; Ikeda, T.; Matsushita, T.; Wake, K.; Sato, T.; Sato, T.; Inoue, H. Inhibitory effect of glycyrrhizin on lipopolysaccharide and D-galactosamine-induced mouse liver injury. Eur. J. Pharmacol. 2007, 576, 136-142. [CrossRef] [PubMed]

37. Lin, G.; Nnane, I.P.; Cheng, T.Y. The effects of pretreatment with glycyrrhizin and glycyrrhetinic aicd on the retrosine-induced hepatotoxicity in rats. Toxicon 1999, 37, 1259-1270. [CrossRef]

38. Wang, C.Y.; Kao, T.C.; Lo, W.H; Yen, G.C. Glycyrrhizic acid and 18 $\beta$-glyccyrrhetinic acid modulate lipopolysaccharide-induced inflammatory response by suppression of NF- $\mathrm{B}$ B through PI3K p1108 and p110 $\gamma$ inhibitions. J. Agric. Food Chem. 2011, 59, 7726-7733. [CrossRef] [PubMed]

39. Ukil, A.; Kar, S.; Srivastav, S.; Ghosh, K.; Das, P.K. Curative effect of $18 \beta$-glyccyrrhetinic acid in experimental visceral leishmaniasis depends on phosphatase-dependent modulation of celluar MAP kinases. PLoS ONE 2011, 6, e29062. [CrossRef] [PubMed]

40. Hendrickson, B.A.; Gokhale, R.; Cho, J.H. Clinical aspects and pathophysiology of inflammatory bowel disease. Clin. Microbiol. Rev. 2002, 15, 79-94. [CrossRef] [PubMed]

41. Murthy, S.N.; Cooper, H.S.; Shim, H.; Shah, R.S.; Ibrahim, S.A.; Sedergran, D.J. Treatment of dextran sulfate sodium induced murine colitis by intracolonic cyclosporine. Dig. Dis. Sci. 1993, 38, 1722-1734. [CrossRef] [PubMed]

42. Kim, S.J.; Kim, M.C.; Um, J.Y.; Hong, S.H. The beneficial effect of vanillic acid on ulcerative colitis. Molecules 2010, 15, 7208-7217. [CrossRef] [PubMed]

43. Hamamoto, N.; Maemura, K.; Hirata, I.; Murano, M.; Sasaki, S.; Katsu, K. Inhibition of dextran sulphate sodium (DSS)-induced colitis in mice by intracolonically administered antibodies against adhesion molecules (endothelial leucocyte adhesion molecule-1 (ELAM-1) or intercellular adhesion molecule-1 (ICAM-1)). Clin. Exp. Immunol. 1999, 117, 462-468. [CrossRef] [PubMed]

Sample Availability: Samples of the compounds are not available from the authors.

(C) 2016 by the authors; licensee MDPI, Basel, Switzerland. This article is an open access article distributed under the terms and conditions of the Creative Commons Attribution (CC-BY) license (http://creativecommons.org/licenses/by/4.0/). 